\title{
Effect of plan layout on the sediment control efficiency of slit-check dams for stony type debris flows mitigation
}

\author{
M. Silva ${ }^{1}$, S. $\operatorname{Costa}^{1} \&$ A. H. Cardoso ${ }^{2}$ \\ ${ }^{1}$ AQUALOGUS, Engenharia e Ambiente, Lda., Portugal \\ ${ }^{2}$ CEHIDRO, Instituto Superior Técnico, Universidade de Lisboa, \\ Portugal
}

\begin{abstract}
There has been an increasing acknowledgement of debris flows as one of the most relevant geomorphic modifiers of many steepland valleys and fans. Despite it being a well-known phenomenon, debris flows are somehow unpredictable and complex to simulate. Due to several past harmful debris flows worldwide, there are already a significant number of mitigation structures with water and sediment control functions, which are essential features of short-term countermeasures against debris flows.

This paper is based on laboratory experiments carried out to test slit dams (open-type retention dams), usually used as a structural countermeasure to mitigate debris flows in steep torrential channels. Flume tests were conducted using a straight channel to assess the influence of different slit-dam solution types on the sediment retention efficiency against stony-type debris flows. Inspired by common slit dam solutions, two different piers layouts in plan view were tested. The experiments were performed with two different discharges and two different slopes. Experimental results about the sediment control efficiency are presented for the different tested solutions.

Keywords: slit check-dam, debris flow, experimental study, sediment control efficiency, plan layout.
\end{abstract}

\section{Introduction}

Debris flows are one of the most dangerous and destructive water-related phenomena, inducing massive disasters in mountainous areas all over the world, 
frequently including the loss of human lives. Therefore, these phenomena have attracted the attention not only by the society but also by the scientific community, resulting in the appearance of detailed studies for several debris-flow related topics, such as its genesis, behaviour and mitigation measures.

Debris flow mitigation measures are usually classified as structural and non-structural. Regarding to structural solutions, the most common is to construct check dams and to perform channel works $[1,2]$. These solutions intend to control the transport and deposition processes of the sediments carried downstream by debris flows. Since check dams are considered as one of the simplest and most effective engineering measures against debris flows by many authors (e.g. $[3,4])$, they were widely applied all over the world as a short-term mitigation measure.

However, due to their reduced storage capacity and poor permeability, closed type check dams are usually backfilled with sediment deposits transported by modest discharges before destructive debris flows occur. In fact, according to several historical records (e.g. [2, 5-7]), closed-type check dams tend to fail its function in a few years after their construction. In order to overcome this ineffective behaviour, open-type check-dam solutions have been developed since half of the $20^{\text {th }}$ century and they are widely used at present in countries such as Austria, Japan, and Taiwan [8-10].

In fact, whenever properly designed and employed, open-type check dams present a major function that the closed-type check dams lack: they allow finer (harmless) sediments to pass through, while trapping larger blocks with greater destructive capability. Consequently, they are preferable over closed-type check dams not only for their effectiveness during debris flow events but also for conserving as much as possible the natural environment and the landscape of mountain torrents, reducing the long-term downstream effects on morphological evolution $[1,2,10]$.

Open-type check dams can be materialized by many different solutions, mainly defined according to their functional openings' shape and building materials (e.g. slit dams, slot dams, grid dams). Regarding to slit dams, they can present single or multiple functional openings which are usually vertical (slit), going from the dam's base up to the top. For a dam with multiple slits, the piers are usually materialized by concrete or steel solutions.

The effectiveness of the slit dams in debris flows mitigation has been proven in several studies (e.g. [1, 2, 8, 11-14]). All those studies concluded that free spacings between the piers can be defined in order to decrease the debris flow peak discharge and to allow the non-harmful sediments to pass through freely, while catching the harmful sediments upstream of the dam. However, despite of several experimental and numerical studies already performed, the uncertainty typically associated with the design of open type structures for debris flow mitigation still persists.

Following the former study reported in Silva et al. [15], focused on evaluating the sediment control efficiency of different slit-dam configurations (as regards to piers shape and free spacing) to mitigate stony-type debris flow, the objective of this paper is to present and discuss the results of further experimental tests 
performed to assess the influence different piers layout solutions in plan view for the sediment trapping efficiency of slit-check dams.

Accordingly, the experimental results which were previously presented and discussed in Silva et al. [15] for a usual slit-dam solution (i.e. transverse to the flow direction of piers plan layout) are herein considered as the reference results, and thus they were compared with the results for another piers layout solution in plan view for the same experimental conditions.

\section{Experimental setup and procedure}

\subsection{Objectives of the experimental study}

In accordance with the aim of the present study, an experimental facility was designed and built in order to perform tests to assess the influence of different slitdam solutions on the sediment control efficiency to mitigate stony-type debris flows.

The design of the experimental setup was consistent with the type of the debris flows that occurred in Madeira Island, Portugal, in February 2010.

Besides the thirty three (33) flume tests which were reported in Silva et al. [15], eight (8) more flume tests were performed with a different solution of piers layout in plan view.

All flume tests were performed focusing on the assessment of the following main issues:

- $\quad$ Trapping efficiency of different slit-dam solutions;

- $\quad$ Slit-dam upstream deposition.

\subsection{Experimental setup}

The experiments were carried out at the Hydraulics Laboratory of Instituto Superior Técnico, Universidade de Lisboa, Portugal.

The experimental facility (Figure 1) comprised a $3.5 \mathrm{~m}$ long and $0.5 \times 0.5 \mathrm{~m} \mathrm{x} \mathrm{m}$ square cross-section flume, representing an approximation of a 1/30 scale model of the central cross-section reach of Ribeira de São João, Madeira Island. The flume slope, $i$, was adjustable between $3.5 \%$ and $26.5 \%$ and was endowed with a water recirculating system.

The flume was equipped with a sediments feeding system composed by a hopper, a conveyor belt and a tilted PVC plate which guaranteed the solid material input at the upstream cross-section of the flume.

Immediately downstream of the flume, a sieve was installed which sorted the water from the solid material passing through the slit-dam. The slit-dam was placed at $\approx 0.60 \mathrm{~m}$ upstream of the flume downstream end.

\subsection{Experimental procedure}

Prior to each run, a given slit-dam (defined by the piers shape, free spacings and piers layout in plan view) was installed and the bottom of the flume was roughened through an erodible $5 \mathrm{~cm}$ deep layer of the same gravel as the gravel used as feeding material. 


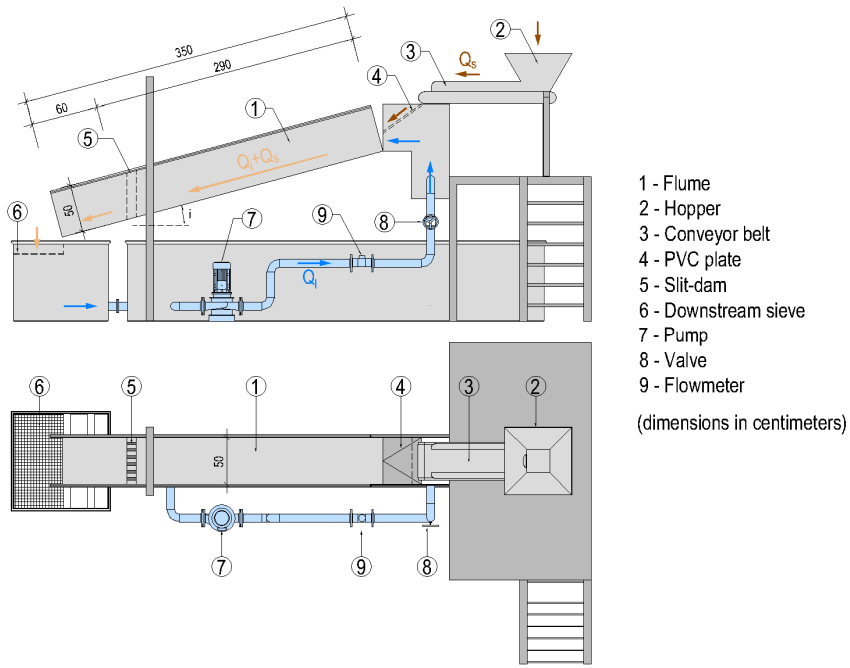

Figure 1: Scheme of the experimental setup.

The flume was continuously fed with water and gravel, resulting in a steady stony-type debris flow, which continued its movement downstream until the slit-dam or the sieve. The total volume of gravel involved in each run, $V_{e}$, including the $5 \mathrm{~cm}$ layer and the fed gravel, was approximately $0.525 \mathrm{~m}^{3}$, ensuring that the flume storage capacity (upstream of the slit dam) was not exceeded. The material fed (excluding the $5 \mathrm{~cm}$ layer) in each run was discharged from the hopper into the conveyor belt, falling into a tilted PVC plate, which ensured a sediment gravity driven input into the flow at the upstream cross-section of the tilting flume.

The inputs of any experiment were the apparent volume (including voids) of sediments involved, $V_{e}$, the slope of the flume, $i$, and the water discharge, $Q_{l}$.

At the end of each test, the total volume of the discharged gravel (which passed through the slit dam) was measured in order to assess the slit dam trapping efficiency.

The debris flow deposition depths were measured with an adapted point gauge at five (5) different points (12.5 cm spaced) per cross-section for twelve (12) crosssections.

Additionally, debris flow deposition patterns and other qualitative aspects were assessed by a photo camera.

After each run, the main outputs were:

- Volume of sediments passing through the slit-dam $\left(V_{s}\right)$;

- Gravel deposition depths upstream of the slit-dam.

\subsection{Physical properties of the gravel}

The solid material used in the experiments was composed by "naturally worn" gravel. It was defined by approximately scaling down, at a $1 / 30$ scale, the sediments of Ribeira de São João, characterized through a field survey of a 4 
meters deep deposits sample. The gravel grain size distribution is shown in Figure 2. It is worth noting that the minimum sediment dimension was limited to $5 \mathrm{~mm}$ in order to prevent sediment recirculation, and hence avoid damage into the pumping system.

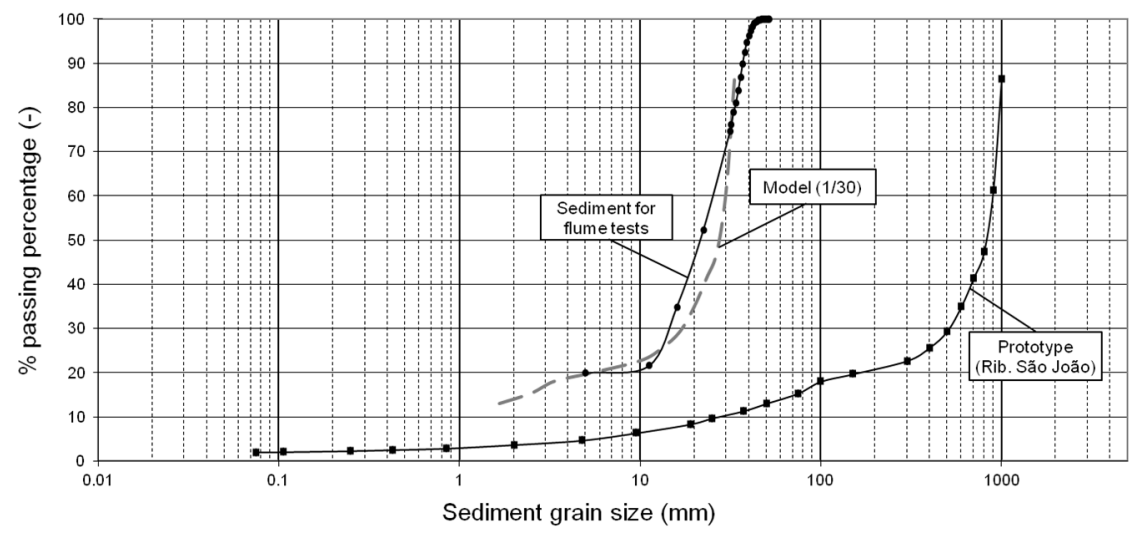

Figure 2: Grain size distribution of sediments.

The main physical properties of the gravel are also presented in Table 1, where $\rho_{\mathrm{r}}=\rho_{\mathrm{s}} / \rho$ is the relative sediment density, $d_{\max }$ is the maximum diameter, $d_{50}$ is the median diameter, $d_{n}$ is the sieve diameter such that $n \%$ by weight is smaller and $\phi_{s}$ is the internal friction angle.

Table 1: Main physical parameters of the solid material used in the experiments.

\begin{tabular}{cccccc}
\hline$\rho_{\mathrm{r}}$ & $\mathrm{d}_{\max }(\mathrm{mm})$ & $\mathrm{d}_{95}(\mathrm{~mm})$ & $\mathrm{d}_{84}(\mathrm{~mm})$ & $\mathrm{d}_{50}(\mathrm{~mm})$ & $\phi_{\mathrm{s}}(\mathrm{deg})$. \\
\hline 2.65 to 2.70 & 52 & 39 & 35 & 21 & 34 \\
\hline
\end{tabular}

The mean Corey shape factor of the material used in the experiments, which characterizes the sphericity of the individual particles was $\mathrm{SF}=0.61$. SF is given by

$$
\mathrm{SF}=\frac{\mathrm{d}_{3}}{\sqrt{\left(\mathrm{d}_{1} \mathrm{~d}_{2}\right)}}
$$

where $d_{1}, d_{2}$ and $d_{3}$ are respectively the longest, the medium and the smallest diameter measured along three perpendicular axes.

It should be noted here that the value of SF for natural sand is $\approx 0.7$, while it must be slightly smaller for large blocks since, in nature, they undergo much shorter rolling and abrasion processes than sand. In other words, the solid material used in the experiments is believed to reproduce the overall shape of natural debris flow blocks. 


\subsection{Characteristic variables of the experimental study}

As previously mentioned, the aim of this paper is to present and discuss the efficiency of a different slit-dam solutions regarding to piers layout in plan view.

Accordingly, results from run tests at the same experimental conditions (as regards to water discharge, initial bed slope, grain size distribution, piers shape, relative spacing and slit-density) were compared for two (2) different slit-dam solutions:

- $\quad$ transverse layout (see Figure 3(a));

- $\quad$ upstream looking V-shaped layout - hereafter called V-shaped layout (see Figure 3(b)).

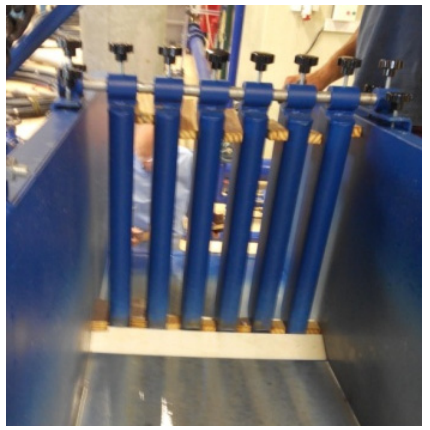

(a)

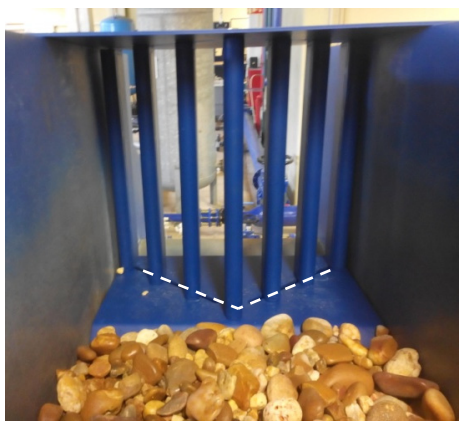

(b)

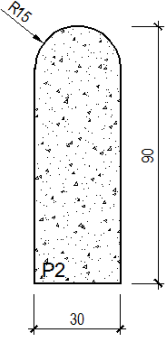

(c)

Figure 3: Slit-dams in flume. Tested plan layouts and adopted piers shape (dimensions in millimetres). (a) Transverse layout; (b) V-shaped layout; and (c) Piers shape.

Following the former experimental tests reported in Silva et al. [15], flume tests with V-shaped layout were carried out for two different slopes, $i$ : $10 \%$ and $20 \%$ and two different water discharges, $Q_{l}: 11 \mathrm{ls}^{-1}$ and $18 \mathrm{ls}^{-1}$. Gravel feeding rates were the same as those previously defined in flume tests for transverse layout, and hence varying between $\approx 3 \mathrm{l} / \mathrm{min}$, for $Q_{l}=11 \mathrm{ls}^{-1}$ and $i=10 \%$, and $\approx 20 \mathrm{l} / \mathrm{min}$, for $Q_{l}=18 \mathrm{ls}^{-1}$ and $i=20 \%$.

The free spacing, $s$, between the piers was defined according to the grain size distribution of sediments used in the flume tests, considering $d_{95}$ as the reference length. The relative spacing values between the piers, $s / d_{95}$, for the V-shaped layout tests were also defined following the experimental activity reported in Silva et al. [15] and they are within the range reported in former experimental studies (e.g. $[1,2,8,11])$ for open-type dams (namely slit and grid dams). Consequently, two (2) different relative spacings were tested -1.18 and 1.49 for the V-shaped layout. The relative spacing of 0.92 were also tested in order to complement the study with more information.

Therefore, the efficiency of two slit-dam solutions with different piers plan layouts were assessed based on the results of several experiments, for different combinations of variables mentioned above and summarized in Table 2. 
Table 2: Characteristic experimental tests variables.

\begin{tabular}{cccc}
\hline piers plan layout & $i(\%)$ & $Q_{l}\left(1 \mathrm{~s}^{-1}\right)$ & $s / d_{95}$ \\
\hline transverse & $10 ; 20$ & $11 ; 18$ & $1.18 ; 1.36 ; 1,49$ \\
\hline $\boldsymbol{V}$-shaped & $10 ; 20$ & $11 ; 18$ & $0.92 ; 1.18 ; 1,49$ \\
\hline
\end{tabular}

\section{Experimental results and analysis}

\subsection{Preliminary remarks}

In this study, the sediment trapping rates were obtained for the performed flume tests in order to assess the efficiency of each solution.

The sediment runoff rate, $S$, is defined as the ratio of the sediment runoff volume passing through the slit-dam, $V_{s}$, to the supplied sediment volume, $V_{e}$ :

$$
\mathrm{S}=\frac{\mathrm{V}_{\mathrm{s}}}{\mathrm{V}_{\mathrm{e}}}
$$

Sediment trapping rate or efficiency, $E$, is defined as the ratio of the sediment retained by the slit-dam $\left(V_{e}-V_{s}\right)$ to the supplied sediment volume, $V_{e}$. It is given by:

$$
\mathrm{E}=1-\mathrm{S}
$$

\subsection{Trapping efficiency}

Figure 4 shows the relationship between the sediment trapping efficiency, $E$, and the relative spacing $s / d_{95}$ for the tested layout solutions. The results of sediment trapping efficiency for transverse and V-shaped layouts are also presented in Table 3 , for eight (8) different experimental conditions.

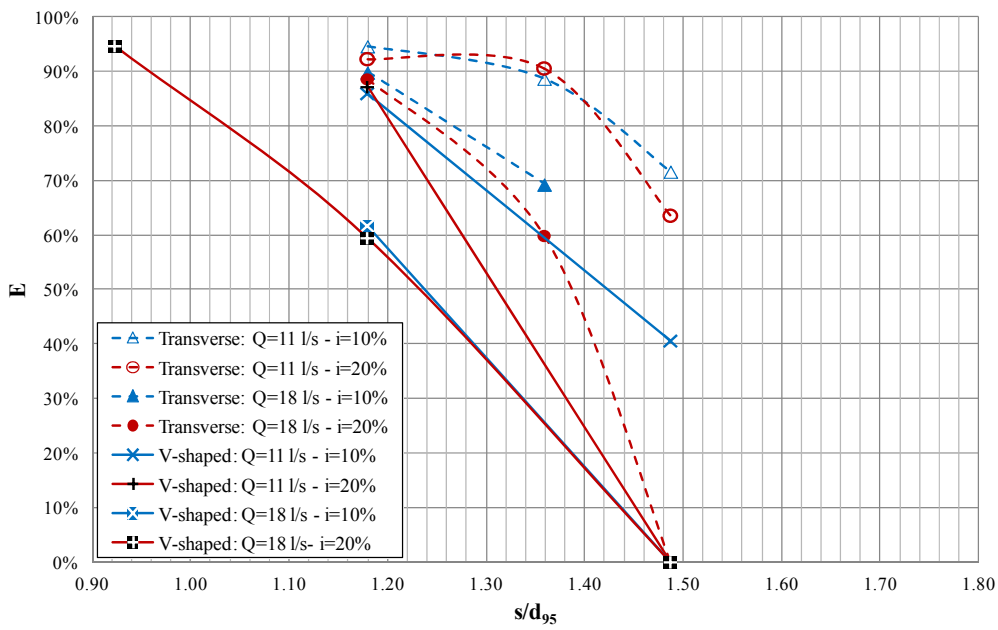

Figure 4: Sediment trapping efficiency results for both plan layout solutions. 
Table 3: Sediment trapping efficiency results.

\begin{tabular}{|c|c|c|c|c|c|c|c|c|}
\hline \multirow[b]{2}{*}{$\begin{array}{l}\text { Run } \\
\text { tests }\end{array}$} & \multirow[b]{2}{*}{$\underset{\left(\mathbf{l s}^{-1}\right)}{Q_{l}}$} & \multirow[b]{2}{*}{$\begin{array}{c}i \\
(\%)\end{array}$} & \multirow[b]{2}{*}{ Pier } & \multirow[b]{2}{*}{$\begin{array}{c}S \\
(\mathbf{m m})\end{array}$} & \multirow[b]{2}{*}{$s / d_{95}$} & \multirow[b]{2}{*}{$\Sigma \mathrm{s} / \mathrm{B}$} & \multicolumn{2}{|c|}{ Efficiency $E(\%)$} \\
\hline & & & & & & & $\begin{array}{c}\text { Transverse } \\
\text { layout }\end{array}$ & $\begin{array}{l}\text { V-shaped } \\
\text { layout }\end{array}$ \\
\hline 1 & 18 & 20 & $\mathrm{P} 2$ & 46 & 1.18 & 0.64 & $89 \%$ & $59 \%$ \\
\hline 2 & 18 & 10 & $\mathrm{P} 2$ & 46 & 1.18 & 0.64 & $90 \%$ & $62 \%$ \\
\hline 3 & 11 & 20 & $\mathrm{P} 2$ & 46 & 1.18 & 0.64 & $92 \%$ & $87 \%$ \\
\hline 4 & 11 & 10 & $\mathrm{P} 2$ & 46 & 1.18 & 0.64 & $95 \%$ & $86 \%$ \\
\hline 5 & 18 & 20 & $\mathrm{P} 2$ & 58 & 1.49 & 0.70 & $\sim 0 \%$ & $\sim 0 \%$ \\
\hline 6 & 11 & 10 & $\mathrm{P} 2$ & 58 & 1.49 & 0.70 & $72 \%$ & $41 \%$ \\
\hline 7 & 11 & 20 & $\mathrm{P} 2$ & 58 & 1.49 & 0.70 & $64 \%$ & $\sim 0 \%$ \\
\hline 8 & 18 & 20 & $\mathrm{P} 2$ & 36 & 0.92 & 0.58 & - & $95 \%$ \\
\hline
\end{tabular}

It is clear that, for the same experimental conditions, $\mathrm{V}$-shaped layout presents lower efficiencies than the transverse layout. The difference seems to be more notable for higher debris flow transport capacity conditions (run tests 1 and 2). On the other hand, for a given relative spacing, differences in sediment trapping rates tend to be less dependent of the plan layout solution for lower transport capacity conditions (run tests 3 and 4 ).

The results obtained for the run tests 4 and 6 also suggest that efficiency of Vshaped layout is more influenced by the relative spacing than the transverse one, even for the lower flow transport capacity regime. In fact, for the $\mathrm{V}$-shaped layout, an increase in relative spacing, $s / d_{95}$, from 1.18 to 1.49 resulted in an approximately half efficient solution. This aspect is even more remarkable comparing the results of run tests 3 and 7 , once $\mathrm{V}$-shaped solution decreased from an $87 \%$ sediment trapping rate solution for a null one.

Moreover, the results clearly suggest that, for the tested experimental conditions, transverse layout is effective to mitigate stony-type debris flows whenever relative spacings of 1.0 to 1.4 were adopted. On the contrary, V-shaped layout showed low efficiencies for higher transport capacity flow regimes, even for a 1.18 relative spacing. In fact, the results of run test 8 suggest that it is necessary reduce the relative spacing to 0.92 in order to attain a V-shape solution with almost the same efficiency of a transverse layout solution with a relative spacing of 1.18 .

The remarkable differences in sediment trapping rates of transverse and $\mathrm{V}$-shaped layouts seem to result mainly from the following issue: $\mathrm{V}$-shaped layout tends to take longer to clog the free spacings between the piers than the transverse layout. According to the performed experimental tests with the V-shaped layout, blocks which collide with the piers tend to become aligned to the preferential flow paths (Figure 5) between the piers and, frequently, to be deflected towards the sidewalls of the flume. This proneness is more evident for higher flow transport 
capacity conditions, once sediments arrive to the slit-dam section with higher velocities, explaining the remarkable reduction in sediment trapping rates which V-shaped solution presents comparing with the transverse solution.

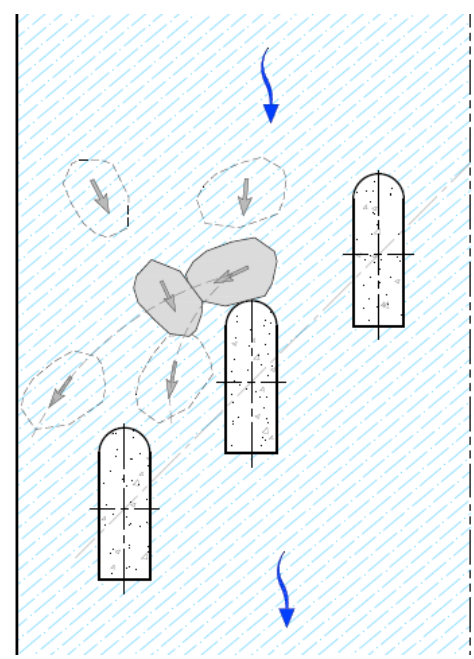

(a) V-shaped layout.

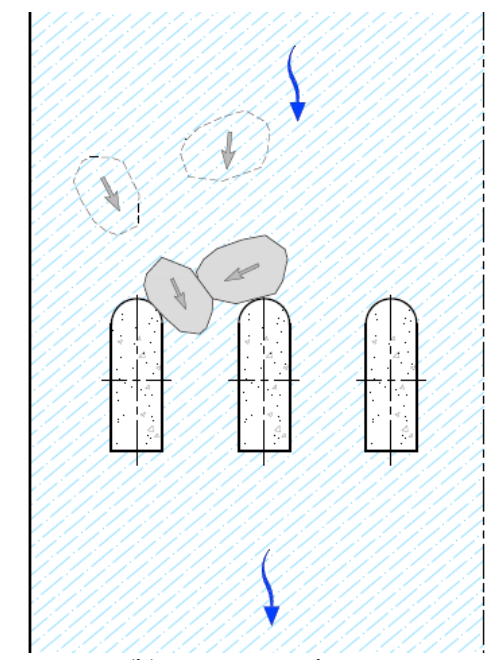

(b) Transverse layout.

Figure 5: Schematic illustration of different situations due to simultaneous arrival of two gravels for $\mathrm{V}$-shaped and transverse layouts.

Furthermore, flume sidewall effects may be non-negligible. Actually, the walls seem to enhance the sediments runoff, once a significant amount of particles tend to pass through the free spacings between the sidewalls of the flume and the closest piers. This effect shall be carefully assessed in the future.

\subsection{Slit-dam upstream deposition}

Figure 6 shows a comparison of the mean longitudinal bed profiles upstream of slit-dam considering V-shaped or transverse layouts for four (4) different experimental conditions (run tests 1 to 4 presented in Table 3 ).

The results presented in Figure 6 suggest that, for the tested solutions, piers plan layout has no significant influence on deposition pattern upstream of the slitdam. Actually, run tests 3 and 4 - Figure 6(c) and (d) respectively - show almost coincident mean bed profiles for the two tested plan layout solutions. Regarding to run tests 1 and 2 - Figure 6(a) and (b) respectively - it should be pointed that, comparing the results for transverse and V-shaped layouts, the notable differences in mean bed profiles are mainly due to significantly different sediment control efficiencies for higher transport capacity conditions. In fact, for the run tests 1 and 2 , the deposition bed profile measurements performed along the experimental run time (namely at 10 and 20 minutes after the begging of the experimental run tests 1 and 2 respectively) confirmed that deposition pattern is very similar for the two tested layout solutions, while the final retained volumes are rather different. 


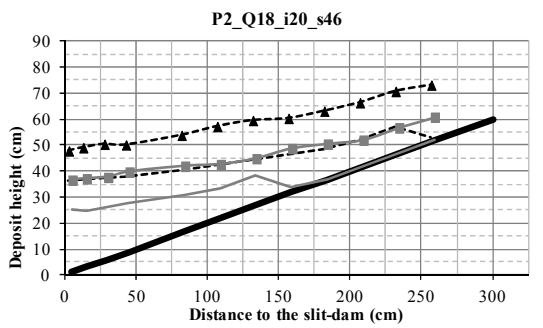

----- Transverse (after 10 minutes) — V-shaped (after 10 minutes)

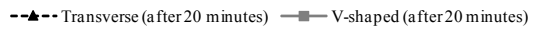

(a) Run test 1.

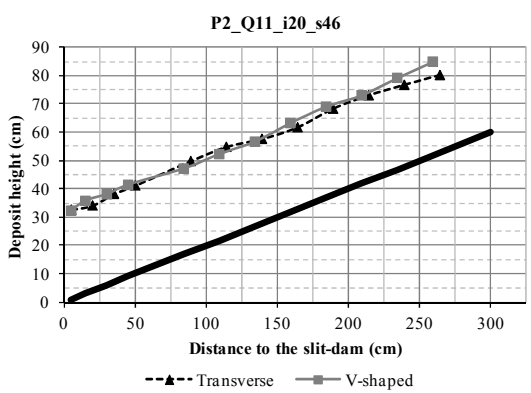

(c) Run test 3.

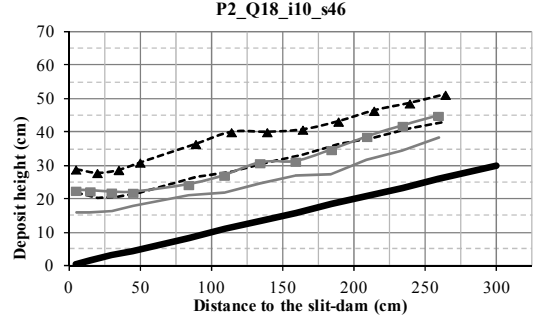

----. Transverse (after 20 minutes) — V-shaped (a fter 20 minutes) --\$ - Transverse (after 34 minutes) $\longrightarrow$ - V-shaped (after 34 minutes)

(b) Run test 2.

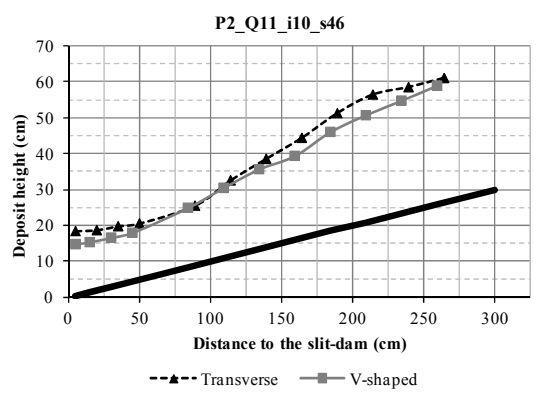

(d) Run test 4 .

Figure 6: Comparison of sediment deposit profiles upstream of the slit-dam for transverse and V-shaped layouts.

On the other hand, the results presented in Figure 6 also show that transport capacity of the flow regime is responsible for different deposition patterns upstream of the slit-dam. In fact, for the highest transport capacity conditions which were tested - run test $1\left(Q_{l}=181 \mathrm{~s}^{-1}\right.$ and $\left.i=20 \%\right)$ - there was a remarkable bed slope decrease due to sediment deposition upstream of the dam for both plan layout solutions (see Table 4). Results also suggest that this process is progressively reduced for lower transport capacity. Actually, for the lowest transport capacity conditions which were tested - run tests 4 and $6\left(Q_{l}=11 \mathrm{ls}^{-1}\right.$ and $i=10 \%$ ) - there was a significant bed slope increase due to the gravel deposition upstream of the flume. Herein, it is worth noting that once sediments deposition upstream of the slit-dam progresses, percolating flow through the voids of the gravel deposits increases, reducing significantly the transport capacity of the flow regime and, hence, promoting the sediments deposition along the whole flume. 
Table 4: Mean bed slopes results due to gravel deposition upstream of the slitdam.

\begin{tabular}{cc|cccccc}
\hline & \multirow{2}{*}{ Plan layout } & \multicolumn{7}{|c}{ Run tests } \\
\cline { 3 - 8 } & $\mathbf{1}$ & $\mathbf{2}$ & $\mathbf{3}$ & $\mathbf{4}$ & $\mathbf{6}$ & $\mathbf{7}$ \\
\hline Initial bed slope $\boldsymbol{i}(\%)$ & $\begin{array}{c}\text { Transverse } \\
\text { and V-shaped }\end{array}$ & 20.0 & 10.0 & 20.0 & 10.0 & 10.0 & 20.0 \\
\hline $\begin{array}{c}\text { Final average bed } \\
\text { slope } \boldsymbol{i}_{\boldsymbol{f}} \mathbf{( \% )}\end{array}$ & Transverse & 10.0 & 8.6 & 18.3 & 16.4 & 13.8 & 19.8 \\
\cline { 2 - 8 } & V-shaped & 9.5 & 8.8 & 20.7 & 17.4 & 12.7 & - \\
\hline
\end{tabular}

\section{Conclusions}

The present experimental study demonstrates that efficiency of slit-dams to mitigate stony type debris flows is influenced by various variables, most of them previously studied by several authors (e.g. $[1,2,8,9,11,12,15])$, including the piers layout in plan view.

Actually, comparing the two tested plan layout solutions, experimental results suggest that transverse piers layout are more appropriate to mitigate stony-type debris flow than the $\mathrm{V}$-shaped solution. In fact, for the same experimental conditions, V-shaped layout tends to take longer to clog the free spacings between the piers due to the tendency for the blocks to get the longer axes aligned with the flow direction.

Experimental results also show that plan layout solutions have no significant influence on the deposition pattern upstream of the slit-dam. However, debris flow transport capacity (which, in the present study, outcomes from a combination of water discharge and bed slope) does influence the deposition pattern.

The influence of different plan layouts for the efficiency of the slit-dams shall be assessed in the future for other layout solutions and debris flow regimes.

\section{Acknowledgements}

The experimental activity is part of the R\&D project STOPDEBRIS, which was funded by QREN and developed by a multidisciplinary team from AQUALOGUS, Engenharia e Ambiente, with partnership of CEHIDRO-IST.

\section{References}

[1] Wenbing, H. \& Guoqiang, O., Efficiency of Slit Dam Prevention against Non-Viscous Debris Flow. Wuhan University Journal of Natural Sciences, 11(4), pp. 865-869, 2006.

[2] Lien, H., Design of Slit Dams for Controlling Stony Debris Flows. International Journal of Sediment Research, 18(1), pp. 74-87, 2003. 
[3] Zeng, Q. L., Yue, Z. Q., Yang, Z. F. \& Zhang, X. J., A case study of long-term field performance of check-dams in mitigation of soil erosion in Jiangjia stream, China. Environmental Geology, 58, pp. 897-911, 2008.

[4] Remaître, A., van Asch, T. J., Malet, J. P. \& Maquaire, O., Influence of check dams on debris-flow run-out intensity. Natural Hazards and Earth System Sciences, 8, pp. 1403-1416, 2008.

[5] Maricar, F., Hashimoto, H., Ikematsu, S. \& Miyoshi, T., Effect if two successive Check Dams on Debris Flow Deposition. Italian Journal of Engineering Geology and Environment, pp. 1073-1082, 2011.

[6] López, J. L., Hernández, D. P. \& Peñaranda, C. V., Presas para el Control de Flujos Torrenciales en el Estado Vargas, Venezuela. Tercer Simposio Regional sobre Hidráulica de Ríos, 2007 (in Spanish).

[7] Hubl, J., Strauss, A., Holub, M. \& Suda, J., Structural Mitigation Measures. Technical Systems and Natural Hazards, 2005.

[8] Takahashi, T., Debris Flow: Mechanics, Prediction and Countermeasures. s.1.: Taylor \& Francis, 2007.

[9] Campisano, A., Cutore, P. \& Modica, C., Improving the Evaluation of Slit-Check Dam Trapping Efficiency by Using a 1D Unsteady Flow Numerical Model. Journal of Hydraulic Engineering, 2014.

[10] Catella, M., Paris, E. \& Solari, L., Case Study: Efficiency of Slit-Check Dams in the Mountain Region of Versilia Basin. Journal of Hydraulic Engineering, Volume 131, pp. 145-152, 2005.

[11] Itoh, T., Horiuchi, S., Mizuyama, T. \& Kaitsuka, K., Hydraulic model tests for evaluating sediment control function with a grid-type Sabo dam in mountainous torrents. International Journal of Sediment Research, 28(4), pp. 511-522, 2013.

[12] Shrestha, B. B., Nakagawa, H., Kawaike, K., Baba, Y., \& Zhang, H., Driftwood deposition from debris flows at slit-check dams and fans. Natural Hazards, 61, pp. 577-602, 2011.

[13] Mizuyama, T., Structural Countermeasures for Debris Flow Disasters. International Journal of Erosion Control Engineering, 1(2), pp. 38-43, 2008.

[14] Armanini, A., Dalrí, C. \& Larcher, M., Slit-Check Dams for Controlling Debris Flow and Mudflow. Disaster Mitigation of Debris Flows, Slope Failures and Landslides, pp. 141-148, 2006.

[15] Silva, M., Costa, S., \& Cardoso, A.H., Slit-check dams for stony type debris flows mitigation. Experimental study to evaluate sediment control efficiency. Dam World Conference, Lisbon 2015. 